\title{
¿POR QUÉ DICEN CIENCIA CUANDO ES TECNOLOGÍA?": NOTA SOBRE EL CONTEXTO SOCIAL DE LA CIENCIA.
}

\section{WHY SAY SCIENCE WHEN TECHNOLOGY? ": NOTE ON THE SOCIAL CONTEXT OF SCIENCE.}

\begin{abstract}
AUTORES
José Miguel Marinas: Doctor en Filosofía. Actualmente es Catedrático de Filosofía Política y Sociología en la Universidad Complutense de Madrid (España). jose.miguel@mixmail.com
\end{abstract}

\section{CURRÍCULUM VITAE}

Doctor en Filosofía. Actualmente es Catedrático de Filosofía Política y Sociología en la Universidad Complutense de Madrid (España).

\section{RESUMEN}

En las siguientes reflexiones se intenta aportar algunas consideraciones críticas sobre el debate en torno a la ciencia, la tecnología y la sociedad. Es esta una simploké de ideas e instituciones que prefiero de momento llamar debate y no materia, aunque no se me escapa que se trata de un campo disciplinar que tiene que ver, de forma inmediata, con los avatares de la enseñanza de la filosofía en el bachillerato en España. Y es que quizá, para llegar a una implantación correcta de este campo de discusión, sea conveniente explicitar algunos de los implícitos que esta relación plantea, de suerte que los mitos queden aireados y los lugares comunes muestren su poder domesticador. 


\title{
PALABRAS CLAVE
}

Ciencia - Tecnología - Contexto social

\begin{abstract}
The following reflections are attempts to provide some critical considerations on the debate about science, technology and society. Is this a simploké of ideas and institutions that prefer to call time discussion and not matter, although I am aware that this is a disciplinary field that has to do, immediately, with the vicissitudes of teaching philosophy in the school in Spain. And perhaps, to reach a correct implementation of this field of discussion, be convenient to explain some of the implicit that this relationship arises, so that myths are airy and public areas to show their trainer.
\end{abstract}

\section{KEY WORDS}

Science - Technology - Social Context

En las siguientes reflexiones se intenta aportar algunas consideraciones críticas sobre el debate en torno a la ciencia, la tecnología y la sociedad. Es esta una simploké de ideas e instituciones que prefiero de momento llamar debate y no materia, aunque no se me escapa que se trata de un campo disciplinar que tiene que ver, de forma inmediata, con los avatares de la enseñanza de la filosofía en el bachillerato en 
España. Y es que quizá, para llegar a una implantación correcta de este campo de discusión, sea conveniente explicitar algunos de los implícitos que esta relación plantea, de suerte que los mitos queden aireados y los lugares comunes muestren su poder domesticador.

Ya sabemos que lo más difícil no es predicar o proponer hacer un trabajo interdisciplinar sino hacerlo. Por eso citaremos una vez más a Roland Barthes (Jeunes Chercheurs, in Communications, $n^{\circ}$ 17) que avisa de algo no suficientemente pensado y es que, cuando hay una convocatoria así, la cosa no consiste en que varias disciplinas ya rutinizadas se disputen un problema, reduciéndolo cada una a sus categorías: hacer un trabajo interdisciplinar es más bien aproximarse, cada uno desde la perspectiva que le es más afín, a un objeto común que propiamente hablando no es de nadie, que por eso ha de ser de todos, a condición de que cada cual entre con conceptos nuevos.

Es evidente que las relaciones entre ciencia, técnica y sociedad forman un nudo de problemas del que la sociología y la filosofía llamadas de la ciencia vienen ocupándose hace varias décadas (desde Bernal a los críticos de Popper, por lo menos). Es cierto también que algunas reflexiones internas de las ciencias aplicadas se desbordan desde sus conceptos a sus contextos: hay físicos, matemáticos y, más recientemente, biólogos que se interesan inmediatamente por las repercusiones sociales de sus hallazgos o por la circulación comercial, esto es política, de sus patentes. Mas quizá es esta una encrucijada para ensayar nuevas formas de nombrar las cosas.

En esta dirección de los problemas, dos puntos tocaré aquí: 1) qué nuevo lugar ocupa el discurso de la ciencia en el contexto de la crisis de la modernización, 2) qué alcance tiene la tecnologización de las formas de saber, que hacen que lo que es mera técnica pase por ciencia. 
Iremos de este modo de los supuestos teóricos a sus aplicaciones pragmáticas y políticas.

\section{SUPERAR LA FRAGMENTACIÓN: RECUPERAR LOS NEXOS ENTRE DISCURSOS}

El suelo de nuestra discusión puede formularse como sigue: El discurso de la ciencia se ha aislado de los demás por efecto mismo de la modernización de las sociedades (hipótesis Habermas, por ej. en Crisis de legitimación en el capitalismo tardío), luego se ha vuelto sobre los demás tipos de saberes (ético, expresivo) con pretensión de reducirlos o colonizarlos. Esta reducción o colonización tiene dos presupuestos no explícitos: que entre los saberes no hay relación de crítica epistémica, que lo que se llama ciencia no es sino su aplicación tecnológica.

El proceso para llegar a esta tensión también podemos reconstruirlo en estos pasos. El conjunto de saberes articulados del orden metafísico-absolutista se quiebra con la transformación de la sociedad: las nuevas técnicas aplicadas a la producción superan la conciencia estamentalista-artesanal y rompen los esquemas de sujeción éticopolítica y expresiva con la aparición de nuevas clases sociales, de nuevos estilos de vida. La ruptura de los antiguos universos simbólicos e ideológicos suponía la destitución de un saber como clave de todos los saberes y prácticas. Pues bien, esta lectura sencilla del proceso -que implicaba el fin de la subordinación de todos los saberes a la metafísica (Comte) o la teología política-, tiene al parecer más vueltas que el haberlas simplificado o tapado no ayuda a reconocer.

La autonomización de la ciencia, por vía de su poder de implantación tecnológica, suponía la aceptación de un implícito -que sigue estando larvado en muchos de los debates sobre la llamada "crisis de la modernidad"- a saber: que lo que eran saberes autónomos, por desgajados del primer tronco común (el saber ético o práctico-moral 
y el saber expresivo o estético), tienen licencia para circular, pero a condición de no cuestionar la autonomía del saber tecnocientífico.

Este enunciado, que supone el acatamiento a la esencia misma del saber moderno (otra cosa son los procesos de modernización social), permite que se deslice otro implícito: no cuestionar la autonomía de los saberes técnicos acaba avalando la idea de que el molde exitoso -técnica y políticamente- que tales saberes imponen troquela o se postula como modelo de los saberes ético y expresivo. Al menos con la difusión de un mismo modo institucional del saber: el del experto. Éticos-politólogos o estetas han de atenerse al modelo técnico en el sentido de acotar la operatividad de sus campos, de sus problemas, de sus técnicas. Si sus modos de pensar o de expresarse requieren otros derroteros (críticos, abiertos o incluso especulativos) tenderán a ser considerados residuos y derivaciones de estilos ya periclitados: no siguen la imparable marcha de la ciencia (que es el nombre, como luego veremos, que se le da a la mera técnica para que se vea más legitimada).

Este argumento no implicaría en modo alguno consagrar la diletancia o la falta de método como campo propio de los saberes humanísticos o filosóficos. Demasiada práctica glosadora de supuestas autoridades hay en estos campos, como para disimularla so capa de profundidad: demasiado talmudismo ajeno a las cosas mismas hay -y que pasa además por investigación- como para consagrar su "anticientifismo" espontáneo (en realidad gremialismo).

Se trata más bien de proponer la reivindicación de dos tareas para el quehacer crítico o, como suelen decir los frankfurtianos, reflexivo (J. Habermas, Conocimiento e interés).

Este saber, ya lo practique el filósofo o el científico natural o social, tiene como objeto inmediato pensar los límites de la propia disciplina y objeto de saber: las ciencias y 
sus aplicaciones técnicas son resultados de operaciones de selección, acotamiento, establecimiento de elementos pertinentes, artificios todos ellos, en suma, que muestran lo alejado de todo naturalismo epistémico que se pretenda. Las cosas no son naturalmente, espontáneamente así, sino como las ciencias las han ido estableciendo.

Este saber o actividad reflexiva atiende a los intereses de la actividad científica o cognitiva. Por eso no se da por supuesta la "evidencia" de las áreas de investigación, por eso no da por fatalmente asentada la separación disciplinar, por eso somete a sospecha la consigna positivista que confunde empiria con experimento, observación espontánea y abierta con establecimiento de observables según criterios de pertinencia no explicitados y convertidos en rutina.

Se trata de no confundir los productos con los procesos. De no cortar los saberes -que aparecen no sólo dotados de lógicas específicas, sino que se revelan como técnicas poderosas por su capacidad de contaminación acrítica- de los intereses sociales concretos que los legitiman.

Lo que estoy sugiriendo es que, además de los trasvases colonizadores que de tanto en tanto se dan de una ciencia (en estado de innovación tecnológica y paradigmática) a los demás campos, cabe hacer una reflexión transversal que cuestione ese reparto de saberes y su modelo implícito. Economicismo, pansexualismo, conductismo son ejemplos de ese desbordamiento con afanes colonizadores que partió de los albaceas de Marx, Freud o Mead. Al igual que en el presente hay un bioeticismo (donde el desagregado tecnicista de los problemas no deja lugar a la reflexión ética hecha no por los supuestos expertos o clérigos sino por los propios interesados), o un cuantitativismo (que confunde significatividad de los problemas con corrección en su tratamiento o traducción estadística). 
Este modo de repensar los implícitos va de las ciencias concretas al plano social e histórico en el que se establece su reparto. No se propone una nueva fusión o confusión de saberes gobernados por un filosofo neo. Se propone una escucha mutua prudente y abierta. Algo que Piaget anunció en los sesenta y que se practica hoy, de modo discreto, en algunos seminarios interfacultativos o interprofesionales.

El ejemplo del nuevo campo de trabajo y enseñanza en el bachillerato es interesante. Sobre todo porque nadie lo entiende como un sustituto de la filosofía. Se trata de otro modo de razonar que puede ser fecundo: pensar problemáticas entrecruzadas sin excluir de ellas sus dimensiones institucionales y profesionales. Frente al expertismo monotemático -hace poco he vuelto a oír, en gente más joven, reivindicar algo diciendo "es mi tema"- puede ser útil entender la implicación recíproca de los problemas.

Esta hipótesis que levanta uno de los más sugerentes pensadores interdisciplinares, él mismo físico, filósofo y sociólogo: Bruno Latour, en su trabajo "Nunca hemos sido modernos" NOTA1.

Más allá de la interpretación que la modernidad reciba en el campo de la glosa filosófica, el problema candente radica en la duración de su mandato de separación de saberes: técnico, ético, expresivo son territorios no comunicables so pena de incurrir en falacias naturalistas (de lo que hay a lo que se debe hacer) o en reduccionismos (por ejemplo los que dicen que las claves éticas y estéticas "no son el fondo más que" epifenómenos de las claves biológicas, las verdaderamente explicativas).

Y es cierto que esa separación de saberes se ha dado como diagnóstico instituyente de la modernidad. Desgajar modos diversos, con alcances precisos, respecto de aquel tronco común, o bóveda barroca con la que solemos pintar el orden del discurso 
clásico (Foucault: Las palabras y las cosas) es en efecto su fruto más duradero. Salvo que en este caso los problemas son complejos y gustan de saltar de una disciplina a otra, implican más saberes que los que juntamos entre todos. La reflexión de los saberes no puede dejar de lado las paradojas, las que superan las dicotomías clásicas. En términos de Bruno Latour.

Fundamentalmente las que percuten en las tareas de los científicos y técnicos no cerrados en lo suyo y que adoptan la posición del tiers instruit (según la expresión de Michel Serres NOTA2). Son paradojas disfrazadas de rutinas que escinden los saberes en ciencia y poder o en analítica e interpretación y que dejan a los practicantes de los Science Studies -a los que texto y contexto no les parecen separables si se quiere pensar con honradez- deseosos de nombrar de manera más integrada las redes que comunican los fenómenos de la crisis y sus potencialidades.

Redes son las conexiones reales, más allá de las disciplinas, aunque no forman, en el sentido convencional, sistema:

Cuando MacKenzie describe la central de inercia de los misiles intercontinentales, cuando Callon describe los electrodos de las pilas de combustible, cuando Hughes describe el filamento de la lámpara incandescente de Edison, cuando yo mismo describo la bacteria del ántrax atenuada por Pasteur o los péptidos del cerebro de Guillemin, los críticos se imaginan que hablamos de ciencia y tecnología. Como éstos son temas marginales o, en el mejor de los casos, manifestaciones de un pensamiento puramente instrumental y de cálculo, los que se interesan por la política o por las almas se sienten justificados para desinteresarse de tales temas. Sin embargo, estas investigaciones no tratan de la naturaleza o del conocimiento, de las cosas-en-sí, sino de la forma en que todas estas cosas están ligadas a las comunidades y a los sujetos. No hablamos del pensamiento instrumental, sino de la base material misma de nuestras sociedades (Nunca Hemos sido modernos, pág. 15. Cursiva mía). 
Esta cita, algo larga, enseña bien el recorrido de la tarea reconstructiva: que la ciencia -que es saber con pretensión de universalidad y completitud- no se agote en las tecnologías que instaura, que la ciencia tienda a explorar, a preguntarse por ese resto (o ese tercero antes excluido) que no es sino la posición de sospechar por lo limitado de una técnica o un modo de hacer. Hasta ahí ha de llegar la ciencia para ser tal: hasta su propia reflexividad.

\section{UBI SOLITUDINEM FACIUNT PACEM APPELLANT}

La situación contextual más abundante, puede caracterizarse como sigue: en el campo de las llamadas ciencias sociales, o humanas o de la conducta, la más de las veces pasa por ciencia la repetición sofisticada (no tanto) de técnicas. Estos procedimientos técnicos y metódicos que han servido para resolver problemas, como lo prueban al menos los ejemplos de Latour, han tenido en muchas ocasiones el carácter de cierre y rutinización. Los métodos, o más bien su empleo acrítico, han ayudado a que se produzca lo que los antiguos dialécticos llamaban una cosificación de los problemas.

El mandato positivista de atenerse a los hechos sigue mostrando su poder. Precisamente un poder que dura porque se ha convertido en un supuesto silencioso, porque opera como un rígido ideal de cientificidad que los científicos sociales atribuyen a los científicos naturales o formales, con más estrechez de la que éstos emplean en su propio trabajo y autodefinición (a veces tantean y buscan más sin preocuparles tanto la homologación disciplinante). Y, en todo caso, porque evita nombrar la perspectiva que constituye toda opción metodológica. 
El positivismo empirista triunfa porque evita pensar. Porque normalmente no se dice que los hechos son hechos de una institución: según un lenguaje, el de un estadio de una disciplina, de unos conceptos operativos. De suerte que los hechos, cargados de contradicciones, tensiones, dotados de zonas oscuras o (aún) no nombrables, aparecen como materiales lavados, neutralizados para ser convertidos en datos o en cuantos, para entrar en modelos cuantificadores.

El fenómeno no es nada nuevo. Es decimonónico (lo cual prueba que seguimos en el terreno de la ciencia, no en el de la instrumentación tecnológica, en esas problemáticas). Es lo que G. Simmel planteaba en su pionero trabajo sobre la ciencia y su poder de troquelado de la mente y la cultura.

Los poderes de la mente se han visto forzados a servir a los propósitos de ganancia pecuniaria de un modo antes inaudito en Alemania, y gobernados por una competencia extraordinariamente activa, tanto nacional como internacional, para lograr que todas las demás cosas se subordinen a los intereses materiales. Como resultado de todo esto, la técnica se ha convertido en los últimos años en la única preocupación de productores y consumidores, y de un modo que es más ominoso para el desarrollo interior y espiritual de la nación. Está completamente olvidado que la técnica es un mero medio para un fin, y su perfección queda excluida cuando se la piensa como uno de los grandes objetos de la raza humana; como si telégrafos y teléfonos fueran en sí mismos cosas de extraordinario valor, pese al hecho de que lo que los hombres se dicen unos a otros por medio de ellos no es en absoluto más inteligente, más noble, o en modo alguno excelente de lo que antes confiaban a medios menos rápidos de comunicación; como si la luz eléctrica elevase al hombre a un estadio más cercano a la perfección, pese al hecho de que los objetos más claramente vistos por medio de aquella son precisamente tan triviales, feos o carentes de importancia como cuando eran vistos gracias al petróleo. Esta primacía de la técnica ha inficionado incluso las ramas puramente intelectuales del conocimiento: 
tanto en las ciencias históricas como en la psicología experimental, investigaciones esencialmente banales $\mathrm{y}$, desde el punto de vista del objetivo final de toda investigación, aún más sin importancia, gozan frecuentemente de un grado muy desproporcionado de reconocimiento, que sólo se lo confiere el que han sido realizadas mediante procedimientos metódicos y técnicos perfectos. ("Tendencias en la vida y el pensamiento alemanes desde 1870". The International Monthly, 1902, vol. 5, pp. 93-111 y 166-184).

No se trata, pues, de negar la tecnología sino de no confundirla con la totalidad de la ciencia. El discurso experto, el que se ve convocado de forma académica o mediática, tiene un sentido y un límite: levantar los problemas y sugerir la modestia de las soluciones. No da, empero, para hablar del sentido de la vida. Ese es el registro de las disciplinas morales o estéticas, en una amplia acepción, que hoy hay que reivindicar. Porque no es evidente que los problemas morales comunes se dejen reducir a repeticiones de códigos o modelos, ni tampoco a fórmulas operativas tomadas de las tecnologías de la ingeniería o la cibernética.

La metis, virtud práctica que pone la astucia junto a la prudencia, tiene hoy un alcance más preciso: no perder calidades, no simplificar, no reducir. Si, como decían los situacionistas, le qualitatif est nôtre force de frappe (lo cualitativo es nuestra fuerza de choque) ello implica que no optamos por la simpleza sino por la sencillez: cada nueva peculiaridad, cada anomalía, cada ejemplo no tratado, cada emergente sin nombre nos interesan. Para probar precisamente que es posible aquella ciencia de lo concreto por la que suspiraba Hegel. Aquella que el estricto Adorno propuso como interés de la filosofía (de la reflexividad):

La situación histórica hace que la filosofía tenga su verdadero interés allí precisamente donde Hegel, de acuerdo con la tradición, proclamó su indiferencia en lo carente de concepto, en lo particular y especial, eso que desde Platón fue 
despachado como perecedero y sin importancia, para serle colgada al fin por Hegel la etiqueta de existencia corrompida. Lo urgente para el concepto es aquello a lo que no llega, lo que el mecanismo de abstracción elimina, lo que no es de antemano un caso de concepto (Dialéctica Negativa, ed. Taurus, p. 16).

Volver del dato a sus condiciones concretas de producción: he ahí la reflexión común de ciencia, tecnología, y teoría crítica de la sociedad.

\section{NOTAS}

NOTA 1: B. LATOUR, Nunca hemos sido modernos, trad. de Purificación Arribas y Fernando Conde, Madrid, ed. Cátedra, 1993. Realicé un comentario más detallado del libro con el título "Pro ingenieris: las redes ocultas de la modernidad" en Isegoría, $\mathrm{n}^{\circ} 8,1994$.

NOTA 2: M. SERRES, Le tiers instruit, París, Bourin, 1991. De este mismo autor se ha publicado en castellano El paso del noroeste en la misma colección dirigida por Nelly Schnaith y Fernando Conde (Ed. Debate, 1992) 